\title{
O livro Cavalo-marinho pernambucano de John Patrick Murphy
}

\author{
Gabriel Ferrão Moreira (UDESC, Florianópolis, SC) \\ gfmoreira@ymail.com
}

Resenha do livro MURPHY, John Patrick. Cavalo-marinho pernambucano. Tradução de André Curiati - Belo Horizonte: Editora UFMG, 2008, 159p. R\$33,00

Palavras-chave: etnomusicologia, antropologia da performance musical, música folclórica brasileira, cavalo-marinho.

\section{The book Cavalo-marinho pernambucano by John Patrick Murphy}

Review of the book MURPHY, John Patrick. Cavalo-marinho pernambucano. Tradução de André Curiati - Belo Horizonte: Editora UFMG, 2008, 159p. R\$33,00

Keywords: ethnomusicology, anthropology of music performance, Brazilian folkloric music, cavalo-marinho.

0 livro Cavalo-marinho pernambucano é uma etnografia musical da prática do Cavalo-Marinho - uma variação regional dos tradicionais folguedos do Bumba-meu-boi, em Pernambuco - escrita, primeiramente como tese de doutorado, pelo etnomusicólogo americano John Patrick Murphy fruto das suas observações nos anos de 1990 e 1991. Originalmente uma tese de doutorado, o texto foi traduzido pelo pesquisador em Etnomusicologia e mestre em linguistica pela USP, André Curiati. 0 trabalho procura estabelecer uma relação entre as transformações nessa prática cultural e as transformações nas relações de trabalho dos participantes (trabalhadores da cana-de-açúcar).

Está dividido em 5 capítulos os quais tratam, respectivamente:

- do contexto social da encenação do cavalo-marinho e a história de vida de mestres brincantes:

- da contextualização do drama em termos de gênero e sumariza seu conteúdo musical e textual;
- da descrição de apresentações rurais e urbanas;

- da análise dos processos musicais e da continuidade histórica que liga o cavalo-marinho

- estudado a outras tradições de performance mais disseminadas no Nordeste brasileiro;

- da interpretação do cavalo-marinho como meio de acesso à visão moral de seus participantes.

Acerca da teoria e metodologia desse trabalho, o autor afirma que se baseia em três pressupostos:

- a música é um elemento básico na cultura e a pesquisa de música pode revelar diversos elementos sobre a cultura em que está integrada.

- a música codifica sentidos através dos sons e pode funcionar como um canal independente de comunicação, aprofundando a textura de uma encenação dramática;

- o contexto de uma apresentação musical é um cenário estrategicamente importante para se estudar processos musicais. 
Através da observação dessas prerrogativas teóricas, Murphy desenvolveu perguntas de pesquisa - e ações no trabalho de campo - que procuravam entender a ligação entre essa performance musical e os valores e visão de mundo de seus participantes, para compreender, assim, 0 significado dessa prática para eles.

A etnografia musical é utilizada como ferramenta de observação na pesquisa narrada no livro. 0 autor vê, dessa forma, a música mais como prática cultural e crê que para ter essa visão do fenômeno deve considerar também sua estrutura apresentada em eventos concretos e seu contexto histórico e social.

Murphy se preocupa em contextualizar geograficamente e historicamente a região na qual ocorre 0 cavalo-marinho, a zona da mata em Pernambuco, narrando a transição do sistema açucareiro do modelo de engenho para o engenho central e, finalmente, as usinas, e procurará demonstrar como a mudança nas relações de trabalho nesse sistema afetou a prática do cavalo-marinho em Pernambuco.

No final do livro há um glossário onde os termos regionais utilizados - nome de instrumentos, gêneros musicais, etc. - são explicados com maior detalhe. Há também um site onde o autor coloca informações adicionais, áudio e vídeos relacionados ao cavalo-marinho. ${ }^{1}$

No primeiro capítulo, 0 contexto social da representação do Cavalo-marinho, Murphy explicita as diversas dimensões constituintes do contexto que envolve a concepção e execução do Cavalo Marinho. Ele discorre acerca das relações de trabalho, demonstrando que a grande maioria dos brincantes ${ }^{2}$ obtém seu sustento das atividades relacionadas ao cultivo e processamento de cana-de-açúcar. Fala acerca das condições de vida simples da grande maioria dos brincantes e da religiosidade que eles possuem - um catolicismo popular embebido em uma crença em feitiçaria e pequenos focos de religiões afro-brasileiras.

As relações entre patrões e empregados desses engenhos na Zona da Mata Norte são consideradas dados importantes pela relação que será estabelecida entre essa dinâmica de trabalho e as representações de algumas personagens do cavalo-marinho. Questões relativas ao baixo nível de instrução dos moradores da Zona da Mata Norte (educação e alfabetização) e os altos índices de violência dessa região também são apontados nesse capítulo para a constituição completa do cenário onde a brincadeira surge e é executada.

Murphy relata a história de vida de dois mestres do cavalo-marinho pernambucano, Mestre Salustiano e Mestre Batista, além de outros mestres menos famosos. 0 autor discorre sobre a organização social do grupo de brincadeira, falando dos diversos papéis dos participantes na organização e representação da brincadeira. Discorre, também, sobre as competências necessárias para que tais funções possam ser assumidas. No fim do capítulo, Murphy relata as diversas maneiras - e as circunstâncias - pelas quais um grupo de cavalo-marinho pode ser formado.

No início do segundo capítulo - Cavalo-marinho: Gênero e seu conteúdo - Murphy usa a categoria "Danças Dramáticas" - termo criado por Mário de Andrade - enquadrando o cavalo-marinho como uma manifestação cultural dessa espécie. De fato, para o autor, o cavalo-marinho se designa como um reisado, uma brincadeira que que tem uma diversidade de cenas e personagens, algumas vezes aleatórios - onde não se perceber sua necessidade para o desenvolvimento do roteiro principal da história - os quais se encerram sempre com o bumba-meu-boi. A partir dessa explanação inicial, o autor trabalha cada uma das três categorias especificamente; os Reisados, 0 Bumba-meu-boi e o Cavalo-Marinho.

Reisado se refere a adaptações dramático-coreográficas de romances e cantigas populares. "Bumba-meu-boi é a designação padrão para danças dramáticas que têm como elemento central a morte e ressurreição de um boi" (p.53). Murphy afirma que segundo Cascudo "bumba é uma interjeição, zás, dando impressão de impacto, pancada, golpe. Bumba significa 'bate, bate com chifre, meu boi'" (p.53). Existem diferentes versões de bumba-meuboi nas regiões do país.

"Cavalo-Marinho é a versão regional do boi de terreiro que é exclusiva da Zona da Mata Norte de Pernambuco e Paraíba" (p.53). Essa dança dramática tem esse nome específico, pois não usa a Zabumba - referência instrumental ao nome Bumba-meu-boi - então o nome da brincadeira foi mudado para outro personagem importante, o cavalo-marinho.

Murphy mostra duas hipóteses para a adoção do nome cavalo-marinho. Uma hipótese é que o cavalo-marinho seria um cavalo importado do além-mar, Portugal. Em várias versões da brincadeira aparece a frase "CavaloMarinho dança muito bem" dando apoio a essa hipótese, de que se refere à presença de um animal de qualidade superior.

A outra hipótese é que Marinho venha do sobrenome de um grande Capitão da Capitania Hereditária da época colonial na região. 0 nome da brincadeira não possui nenhuma relação com o animal cavalo-marinho (p.54).

Nessa seção do capítulo o autor se dedica à diferenciar 0 bumba-meu-boi do cavalo-marinho através das diferenças de instrumentação e entre algumas cenas entre os dramas, como, por exemplo, o uso da rabeca no cavalomarinho e sua ausência no bumba-meu-boi.

Murphy cita Mário de Andrade, Borba Filho e Araújo como as fontes bibliográficas que se completaram para o seu conhecimento do Cavalo-Marinho anterior à pesquisa. 0 autor considerava necessário inserir uma versão 
do que seu informante considerava como apresentação integral do cavalo-marinho, uma vez que cada apresentação era particular, contendo cenas diferentes ou excluindo algumas outras.

A versão do Mestre Salustiano consistia em três partes, descritas com muito detalhamento no livro (p.56-60). A primeira parte é caracterizada pelo embate entre os vaqueiros e o Capitão pela posse do engenho. Após a vitória do Capitão sobre os vaqueiros, esses se tornam seus servos e irão mediar suas relações com os outros personagens restantes. De fato, o resto da brincadeira é a festa do Capitão.

Na segunda parte um grande número de personagens contracenam com o Capitão com o intuito de negociar, mostrar um problema a ser solucionado ou narrar uma odisseia pessoal. No livro, Murphy cita detalhadamente cada personagem que aparece nessa parte (p.57).

$\mathrm{Na}$ terceira parte, os personagens individuais se tornam mais agitados conforme se aproxima a chegada do Boi. Nesse episódio, o Boi avança sobre os brincantes e a plateia, até que 0 vaqueiro Mateus o mata. Depois do funeral do Boi, o médico é chamado para curá-lo. 0 Boi revive e dança outra vez.

Após a sinopse da brincadeira, Murphy comenta acerca do conjunto musical do cavalo-marinho. 0 conjunto musical é formado por um vocalista principal, um ou mais vocalistas de apoio, rabeca, pandeiro, bage ${ }^{3}$, canzá ou reco-reco e ganzá. 0 autor dedicará grande parte do presente capítulo para uma descrição bastante detalhada sobre os instrumentos, principalmente a rabeca, sobre a qual também se preocupa em falar sobre seus fabricantes e especificações da construção do instrumento.

Depois dessa descrição detalhada dos instrumentos, diversos exemplos musicais são mostrados onde os padrões executados por cada instrumento e cantos do toadeiro (cantor principal) são escritos. Murphy considera que a riqueza dos textos falados no cavalo-marinho demanda um estudo à parte e, no fim desse capítulo, também há uma seção onde partes dos textos falados são apresentadas, separados por gêneros, estilos, estratégias de texto e meios de transmissão.

No terceiro capítulo intitulado Cavalo-marinho brincando, o autor descreve os diversos contextos onde o cavalo-marinho é apresentado e as particularidades das apresentações nesses diversos ambientes: apresentações rurais, brincadeiras de rua, apresentações de festa, apresentações urbanas.

Nas apresentações rurais, se joga ${ }^{4}$ em três lugares específicos: (1) na rua, em pequenas cidades independentemente de festas de santos padroeiros, (2) na rua, como parte de festas de santos padroeiros ou (3) em engenhos ou sítios.

Murphy comenta que são raras as apresentações em sítios e engenhos, pela mudança de residência da maioria dos brincantes dos sítios para as cidades. Entretanto, os informantes afirmavam que o sítio era 0 lugar ideal para a execução do cavalo-marinho, onde ele era conhecido e respeitado, sem as restrições das autoridades municipais.

As brincadeiras de rua se aproximam desse ideal, onde os brincantes - geralmente os trabalhadores do cultivo de cana, que agora moram na cidade - acordam com donos de bares o valor pago ao grupo que representará a brincadeira.

Nas apresentações de festa, os grupos são contratados para celebrações comunitárias dedicadas aos santos padroeiros. Já as apresentações urbanas são feitas em número reduzido de locais e são financiadas pela Prefeitura Municipal de Recife. Nessas apresentações organizadas o cavalo-marinho é tratado como folclore - fetichizada como uma prática cultural ancestral preservada, e não como nos engenhos - algo pertencente aqueles que a 'performam' viva dentro do sistema cultural atual que eles vivem. No final do capítulo Murphy afirma que o cavalo-marinho não é brincado no carnaval, onde o Bumbameu-boi é executado.

No capítulo quarto - Processos musicais e continuidade histórica - o autor explicita a importância da música como elemento sustentador da prática do cavalo marinho. Também ressalta a importância da música de dança (música que acompanha a dança das personagens) como elemento de contraste entre as partes faladas. Na página 106 é apresentada uma tabela que organiza os eventos da cena do Soldado - uma das cenas do cavalo-marinho - entre música e diálogo, demonstrando a importância da alternância entre essas duas linguagens. A música tem 0 papel de, na alternância com o texto, estruturar o tempo da performance e preservar a atenção dos ouvintes, bem como conservar a energia dos brincantes.

Após ressaltar a importância da música para o andamento da brincadeira, Murphy descreve a continuidade histórica do cavalo-marinho e as mudanças que ocorreram na sua prática no decorrer da história da Zona da Mata Norte. Ele declara que muitas cenas que foram incluidas ou excluídas da representação refletem mudanças políticas e sociais (criação da CLT, mudança para a cidade, surgimento da televisão, mudanças no processo de produção do açúcar) que interferiram na relação patrão-empregado e também na concepção da mulher.

0 autor mostra a continuidade das tradições do cavalomarinho através da demonstração das semelhanças entre o cavalo-marinho atual e as versões mais antigas copiladas em diversos livros que utilizou como base para a análise da continuidade e mudança no gênero.

Ainda nesse capitulo, Murphy descreve as particularidades do Bumba-meu-boi em Pernambuco (uma vez que, como já dito anteriormente, há várias versões do bumbameu-boi em diversos estados brasileiros). 
No capítulo final, Uma interpretação do cavalo-marinho como visão moral, devoção religiosa popular e arte cômi$\mathrm{ca}$, Murphy revela sua percepção acerca do cavalo-marinho como representação de uma visão moral e devoção religiosa próprias dos camponeses, bem como um produto concebido como artístico.

Ele reitera que para se entender esses significados é imprescindivel ter em mente o contexto no qual se desenvolve a brincadeira, de trabalhadores da cana de açúcar recentemente proletarizados, e dedicará um tópico do capítulo para o entendimento desse fenômeno. Após o esclarecimento desse contexto ele comenta a visão moral contida dentro da representação. A cena da disputa entre o capitão e os vaqueiros pela posse da terra demonstra a punição merecida dos vaqueiros por desobedecerem ao Capitão, e não é uma crítica à atitude enérgica do capitão; é uma visão de respeito à autoridade patronal.

Murphy admite que inicialmente percebeu o cavalomarinho como uma crítica ferrenha ao 'patronato', mas logo compreendeu que a crítica era aos maus patrões e maus empregados, e exaltação daqueles que ocupavam de maneira honesta e justa seus papéis dentro desse sistema. Também se percebe o fundo de devoção religiosa do bumba-meu-boi, a temática da morte e ressurreição do Boi, e a ligação desses com o suprimento das necessidades mais básicas daquelas pessoas.

No fim do capítulo o autor demonstra que a interpretação mais recorrente do cavalo-marinho por seus brincantes é de arte cômica, onde o humor é valorizado e necessário para a existência da brincadeira.

Ele também afirma que, apesar da existência desses elementos morais e religiosos no cavalo-marinho, não há garantia de que todos seus participantes estejam de acordo com essas representações, sendo que muitos deles permanecem na superfície da brincadeira onde os elementos artísticos e cômicos são melhor percebidos. De fato, o cavalo-marinho deve ser percebido nessa sua multiplicidade na possibilidade de interpretação e impacto artístico e, como diz Murphy na página 138, "talvez seja por isso que permanece como uma tradição viável".
A edição do livro Cavalo-marinho Pernambucano é uma iniciativa bastante válida da etnomusicologia brasileira. Muito embora seja uma tradução de uma obra americana, sua edição por uma editora brasileira é uma iniciativa louvável. Entretanto, faltam imagens que seriam essenciais para a descrição dos instrumentos, indumentária e rostos dos informantes principais como Salustiano e Batista.

Pelo fato de ser uma obra escrita originalmente para leitores estrangeiros, relata bastantes coisas que para um 'nativo' no caso um brasileiro - são conhecidas de antemão - como a composição dos instrumentos musicais - tornando a leitura do livro - em algumas dessas seções - um pouco tediosa.

Murphy fez uma extensa pesquisa acerca do cavalo-marinho e sua pesquisa bibliográfica o dotou de um vasto conhecimento do status da brincadeira em outros tempos, o que propiciou sua análise das mudanças e continuidades presentes nas brincadeiras que observou e na prática narrada pelo seu informante principal, Mestre Salustiano.

Contudo, a maneira pela qual ele organiza as informações em seu livro dificulta um entendimento amplo da brincadeira, na medida em que ao trabalhar com o contexto social da representação do cavalo-marinho - no primeiro capítulo - ele cita cenas e personagens da brincadeira quando essa só será explicada no segundo capítulo.

Por fim, o título da obra em inglês (Performing a moral vision) o forte conteúdo etnográfico e a conclusão da obra sendo a interpretação do cavalo-marinho em termos antropológicos - como antropologia da performance - entendo que a obra situa-se dentro da Antropologia da Música, onde a música serve como elemento aglutinador de valores morais, éticos e religiosos daqueles que a executam (musica inserida dentro da cultura - numa visão semelhante à MERRIAM (1964), muito embora haja bastante transcrições musicais e informações sobre instrumentos, não são elaboradas interpretações musicológicas dessas estruturas musicais) de forma diferente da etnomusicologia mais voltada para a interpretação dos signos musicais para o entendimento de como se processam e se desenvolvem dentro de uma cultura particular - também tendendo para uma interpretação do 'humano' por detrás desses signos musicais (BLACKING,1973). 


\section{Referências}

BLACKING, John. How musical is man? Seatle: University of Washinghton Press, 1973.

MURPHY,Jonh Patrick. Cavalo-marinho pernambucano. Tradução de André Curiati - Belo Horizonte: Editora UFMG, 2008, $159 \mathrm{p}$.

MERRIAM, Alan. The anthropology of music. Evanston: Northwestern University Press, 1964.

\section{Notas}

1 web3.unt.edu/murphy/brazil.

2 Categoria nativa que se refere aos participantes do Cavalo-marinho.

3 "A bage é um pedaço de taboca sem nó, de $45-50 \mathrm{~cm}$ por $8,5 \mathrm{~cm}$ da extensão da taboca. Esta superfície serrilhada é friccionada com um bastãozinho de perfil triangular (p.68).

4 Categoria nativa que significa participar do cavalo-marinho.

Gabriel Ferrão Moreira é Mestrando em Música - linha de pesquisa Musicologia-Etnomusicologia pela Universidade do Estado de Santa Catarina - possui graduação em Licenciatura em Música pela mesma universidade (2008). Atualmente pesquisa as representações musicais de brasilidade na obra de Heitor Villa-Lobos, orientado pelo Prof.Dr. Acácio Tadeu de Piedade Camargo. Nessa mesma pesquisa procura orientar-se também, pela disciplina História, onde pôde apresentar seu trabalho no XXV Simpósio Nacional de História na Universidade Federal do Ceará, em 2009. Também trabalha com projetos musicais e organização de eventos musicais na Comunidade Batista de Ingleses, Florianópolis - SC. Tem experiência na área de Artes, com ênfase em Música, atuando principalmente nos seguintes temas: composição, música erudita, musica popular, clássico-romântico e educação musical. É bolsista do CNPQ/CAPES. 